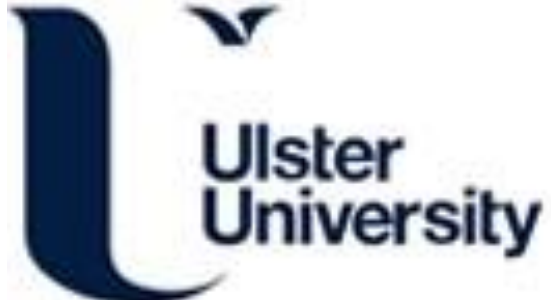

\section{Effect of shock structure on stabilization and blow-off of hydrogen jet flames}

Takeno, K., Yamamoto, S., Sakatsume, R., Hirakawa, S., Takeda, H., Shentsov, V., Makarov, DV., \& Molkov, V. (2020). Effect of shock structure on stabilization and blow-off of hydrogen jet flames. International Journal of Hydrogen Energy, 45(16), 10145-10154. https://doi.org/10.1016/j.ijhydene.2020.01.217

Link to publication record in Ulster University Research Portal

\section{Published in:}

International Journal of Hydrogen Energy

Publication Status:

Published (in print/issue): 20/03/2020

DOI:

https://doi.org/10.1016/j.jjhydene.2020.01.217

\section{Document Version}

Author Accepted version

\section{General rights}

Copyright for the publications made accessible via Ulster University's Research Portal is retained by the author(s) and / or other copyright owners and it is a condition of accessing these publications that users recognise and abide by the legal requirements associated with these rights.

\section{Take down policy}

The Research Portal is Ulster University's institutional repository that provides access to Ulster's research outputs. Every effort has been made to ensure that content in the Research Portal does not infringe any person's rights, or applicable UK laws. If you discover content in the Research Portal that you believe breaches copyright or violates any law, please contact pure-support@ulster.ac.uk. 


\title{
Effect of Shock Structure on Stabilization and Blow-off of Hydrogen Jet Flames
}

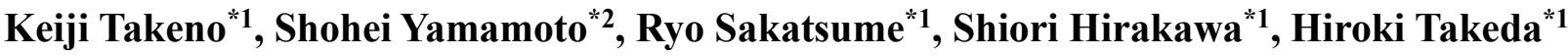 \\ Volodymyr Shentsov*3, Dmitriy Makarov ${ }^{* 3}$ and Vladimir Molkov*3 \\ ${ }^{* 1}$ Department of Advanced Science and Technology, Toyota Technological Institute \\ 2-12-1 Hisakata, Tenpaku-ku, Nagoya 468-8511, Japan \\ ${ }^{* 2}$ Department of Mechanical Systems Engineering, Tokyo University of Agriculture and Technology, \\ 2-24-16 Naka-cho, Koganei-city, Tokyo 184-8588, Japan \\ ${ }^{* 3}$ HySAFER Centre, Ulster University, Shore Road, Newtownabbey, BT37 0QB, U.K.
}

\begin{abstract}
Under-expanded hydrogen jet has characteristic shock structure immediately downstream of the nozzle exit. The shock structure depends on the ratio $p_{E X} / p_{A}$, i.e. the ratio of nozzle exit to ambient pressure, and the distributions of velocity and concentration in an under-expanded hydrogen jet depend on characteristics of the shock structure. Therefore, the shock structure should affect the blow-off behaviour of under-expanded hydrogen jet flame. Since this issue has not been investigated in detail, this study aims to close this knowledge gap. The effect of changes in shock structure on lift-off length and blow-off conditions for non-premixed turbulent hydrogen free jet flame has been experimentally investigated. The shock structure was varied by using three types of nozzles: convergent, straight and divergent nozzles. Inlet diameters of nozzles change from 0.31 to $1.04 \mathrm{~mm}$ and outlet diameters from 0.34 to $1.7 \mathrm{~mm}$. The static pressure and the ratio of cross-section area at the nozzle inlet to that at the outlet were varying parameters in this study. Hydrogen was horizontally spouted through a nozzle to atmosphere. The maximum static pressure in a nozzle was 13.2 MPa. The experiments revealed that when the hydrogen jet had sequential shock cell structures, which occurred in the range of $p_{E X} / p_{A}$ smaller than 2.45, a higher mass flow rate of hydrogen was needed for the stabilization of a jet flame than that for $p_{E X} / p_{A}$ larger than 2.45 and that when closed to the ideal expansion $\left(p_{E X /} p_{A}=1\right)$, the mass flow rate for stable flame became maximum. In addition, it was observed that the lift-off length of stable flames followed with sequential shock cell structures were almost the same when the minimum cross-section area of used nozzles was constant. However, when hydrogen jet had a shock structure with single Mach disk, the lift-off lengths and the minimum mass flow rate required for the stable jet flame were decreasing with the decrease of the cross-sectional area ratio of the nozzle exit to inlet.
\end{abstract}

Keywords: Blow-off, lift-off, non-premixed turbulent flame, under-expanded jet, convergent and divergent nozzles, shock structure

\section{Highlights:}

Hydrogen release tests at pressures up to $13 \mathrm{MPa}$ were conducted.

Three types of nozzle were used: convergent, straight and divergent.

Relationship between shock structure and blow-off characteristics was examined.

Jet flame with multiple diamond shock structure require higher mass flow rate.

Blow-off is controlled by position of stoichiometric contour and flame base. 


\section{Introduction}

Use of hydrogen from renewable sources is a pathway to achieve low carbon society targets, because only water could be exhausted when hydrogen is used as an energy carrier [1]. Therefore, the effective use of hydrogen would be indispensable for building the sustainable society $[2,3]$. Generally, hydrogen is stored under high pressure because under atmospheric pressure it has low volumetric energy density. The pressure in composite vessels is very high and can reach $90 \mathrm{MPa}$ for fuel cell vehicles. If hydrogen is released under such high pressure and ignited, a non-premixed turbulent flame of under-expanded jet can be established. The studies on under-expanded jet flames were performed to establish safety evaluation criteria [4-12]. Takeno et al. carried out experiments under unprecedentedly high static pressure of $80 \mathrm{MPa}$ and revealed that the static pressure required for stable jet flames changes with nozzle diameter, and the jet flame length was expressed as a function of nozzle diameter and static pressure [7-12]. The authors have experimentally examined the relationship between the static pressure and the blow-off conditions and explained the blow-off phenomenon for hydrogen non-premixed turbulent flame originating from under-expanded jet for the case of single Mach disk [13]. However, the experiments in above-mentioned studies were performed using only straight nozzles of constant diameter. Non-premixed hydrogen flames in jets spouted through tapered nozzles whose cross-section area increases or decreases have not been investigated up to now.

The shocks structure generated near the nozzle exit was investigated experimentally and numerically [14-17]. According to review by Franquet et al. [18], the changes in the shocks structure are governed by the ratio $p_{0} / p_{A}$, where $p_{0}$ is the static pressure, and $p_{A}$ is the atmospheric pressure, or by the ratio $p_{E X} / p_{A}$, where $p_{E X}$ is the pressure at the nozzle exit, and can be classified as follows. Moderately under-expanded jets, which have oblique shock waves from a lip of the nozzle exit toward the nozzle axis and its reflected shock waves, are generated in the pressure range $1.1 \lesssim p_{E X} / p_{A} \lesssim 3$. Under-expanded jets in the range $2 \lesssim p_{E X} / p_{A} \lesssim 4$ consist of a barrel shock starting at the nozzle lip and Mach disk. At pressure ratios $4 \lesssim p_{E X} / p_{A}$, jets have single Mach disk and they are called highly under-expanded jets. The change in shocks structure due to change of $p_{E X} / p_{A}$ ratio is thought to give different distribution of spouted gas concentration and velocity field. Thus, the shocks structure could affect the lift-off length and the conditions required for stable non-premixed jet flames.

In the present paper, lift-off lengths and blow-off conditions for expanded hydrogen jet flames were experimentally investigated, and distributions of velocities and hydrogen concentration in unignited hydrogen jets were numerically examined. The variation of the shock structure downstream of the nozzle exit was provided by change of pressure in the stagnation point and the exit from the nozzle. The pressure at the nozzle exit was changed by using divergent or convergent nozzles whose cross-section area linearly increased or decreased in the nozzle axis direction. The relationship between conditions for the sustained jet flame and the shock structure is discussed, and a qualitative model of blow-off for expanded hydrogen jet flame is proposed.

\section{Experimental setup and conditions}

Figure 1 shows a schematic of an experimental setup and an optical measurement system. High-pressurized hydrogen jet was released horizontally by blowdown from a reservoir with maximum pressure of 13.2 MPa. Spouted hydrogen jets were ignited by a pilot natural gas non-premixed flame set at 700 $\mathrm{mm}$ downstream of the nozzle exit. This flame was removed after the jet flame was stabilised. The spouting pressure was adjusted by the valve and measured by a piezo-electric pressure sensor (TP-AR, TEAC) installed between valve and nozzle and the pressure data was collected by $10 \mathrm{kHz}$ digital recorder. Since the maximum 
hydrogen velocity inside hydrogen piping from valve to nozzle was less than several centimetres per second, the measured static pressure was estimated to coincide with the stagnation pressure in the chamber of nozzle.

Table 1 shows the identification and parameters of three types of nozzle, i.e. measured diameters at the nozzle inlet, $d_{I N}$, and exit, $d_{E X}$, cross-section areas at inlet, $A_{I N}$, and exit, $A_{E X}$, as well as their ratio $A_{E X} / A_{I N}$. Three straight, six divergent and one convergent nozzle were used in this study, and their cross-section drawings are shown in Figure 2. For the divergent and convergent nozzles, the minimum diameter of nozzle throat $d_{t h r}$ was almost the same about $0.5 \mathrm{~mm}$ to provide the same hydrogen flow rate.

Light source of the optical system for taking schlieren images was $\mathrm{Nd}: \mathrm{YVO}_{4}$ laser (G50-B, kato koken) with a wave length of $532 \mathrm{~nm}$, a maximum output of $50 \mathrm{~mW}$. A parallel beam of the light for the schlieren imaging was prepared using two concave mirrors with its diameter of $150 \mathrm{~mm}$ and focal length of $1500 \mathrm{~mm}$ (CM series, kato koken). Laser beam of $0.5 \mathrm{~mm}$ diameter was expanded through the spatial filter located at the focal point of first concave mirror. A knife edge was installed at the focal point of second concave mirror, and cut the focus point in perpendicular to the hydrogen flow direction. Schlieren images were taken by a high-speed camera (UX100, Photron) at $2000 \mathrm{fps}$ and exposure time of $12.5 \mu$ s through camera lens (focal length $=200 \mathrm{~mm}$, Nikon).

\section{Experimental results and discussion}

Figure 3 shows a typical schlieren images of hydrogen turbulent non-premixed jet flames obtained in this study at the static pressure of around $8 \mathrm{MPa}$ with different cross-section area ratio, $A_{E X} / A_{I N}$, and the three kinds of nozzle. Hydrogen mass flow rate, $m$, was practically the same in the range of $0.93-1.03 \mathrm{~g} / \mathrm{s}$, which was calculated from the static pressures and cross-section areas, $A_{E X}$ and $A_{I N}$, assumption an isentropic expansion. The lift-off length $H f b$ was defined as the length from the nozzle exit to the time-averaged position of the flame base. For ratios $A_{E X} / A_{I N}<3.78$, the value of $H f b$ increased with the increase of $A_{E X} / A_{I N}$. However, for $A_{E X} / A_{I N} \geq$ 3.78 , the values of $H f b$ were almost constant regardless of $A_{E X} / A_{I N}$.

In order to clearly show the shock wave structure, enlarged images near the nozzle exit were shown in Figure 3 (right column), where pressure ratio, $p_{E X} / p_{A}$, which is the ratio of nozzle exit pressure, $p_{E X}$, to the ambient pressure, $p_{A}$, are also shown. A shock wave structure consisting of a barrel shock and single Mach disk was observed for ratios $A_{E X} / A_{I N} \leq 1.62$. For ratios $A_{E X} / A_{I N}>1$ the nozzle exit pressure $p_{E X}$ decreases as $A_{E X} / A_{I N}$ increases, and a series of shocks (diamond structure) can be seen in images for $A_{E X} / A_{I N} \geq 3.78$. The value of $p_{E X} / p_{A}$ was almost unity as shown in the image for $A_{E X} / A_{I N}=6.44(\mathrm{~d} 0.5-1.30)$, and an over-expanded jet can be seen in the image for $p_{E X} / p_{A}<1(\mathrm{~d} 0.5-1.65)$. The observed variation of shock structure with $A_{E X} / A_{I N}$ and $p_{E X} / p_{A}$ agrees quantitatively with conclusions of previous study [18].

Figure 4 shows the relationship between $H f b$ and $A_{E X} / A_{I N}$ for stable jet flames when using the minimum diameter of nozzle throat, $d_{t h r}$, in the narrow range $0.51-0.53 \mathrm{~mm}$, so that the relationship between hydrogen mass flow rate and static pressure was determined regardless of the nozzle throat type. Hydrogen mass flow rate was in the range $0.40 \leq m \leq 1.48 \mathrm{~g} / \mathrm{s}$ depending on the static pressure of hydrogen, and resulted in the scatter of $H f b$ in Figure 4. For ratios $A_{E X} / A_{I N}>3.78$, the values of $H f b$ for the same $A_{E X} / A_{I N}$ were almost constant regardless of the mass flow rate, and the values of $H f b$ for $A_{E X} / A_{I N}<3.78$ tended to decrease with the decrease in $A_{E X} / A_{I N}$. When $A_{E X} / A_{I N} \sim 3.78$, jet flames were stable in the range of $0.69 \leq m \leq 1.48 \mathrm{~g} / \mathrm{s}$ (equivalent to1.67 $\leq$ $\left.p_{E X} / p_{A} \leq 3.59\right)$, accompanied with sequential shock cell structures shown in Figure 3. Such jet is shown in the image of d0.5-1.00 and is classified as the highly under-expanded jet which occurs in the range of $2 \lesssim p_{E X} / p_{A} \lesssim$ 
4 [18]. For $A_{E X} / A_{I N} \geq 3.78$ the value of $H f b$ was almost constant independent of $A_{E X} / A_{I N}$. This result shows that the value of $H f b$ for all three types of observed in experiments jets (highly under-expanded jet, expanded jet and over-expanded jet), which occur at pressure ratio $p_{E X} / p_{A} \lesssim 2.45$, can be expected to be constant. In addition, for pressure ratio $p_{E X} / p_{A}>2.45$, the value of $H f b$ in highly under-expanded jets accompanied with a barrel shock and single Mach disk can be expected to decrease with the increase of $p_{E X} / p_{A}$ because the decrease in $A_{E X}$ $/ A_{I N}$ causes the increase in $p_{E X} / p_{A}$. Accordingly, the lift-off length $H f b$ depends on the kind of shock structure just downstream the nozzle exit.

Figure 5 shows the conditions for existence of stable hydrogen jet flame and flame blow-off. It is presented in the coordinates "mass flow rate" and "ratio $A_{E X} / A_{I N}$ " for nozzles $0.51 \leq d_{t h r} \leq 0.53 \mathrm{~mm}$. This figure shows that a minimum mass flow rate for the stable jet flame exists, and that the minimum value increases with the increase of $A_{E X} / A_{I N}$ and reaches extreme at $5 \lesssim A_{E X} / A_{I N} \lesssim 7$, where the flow is close to the ideal expansion $\left(p_{E X} / p_{A} \sim 1\right)$. For region $A_{E X} / A_{I N} \lesssim 4$, which is classified as the region of highly under-expanded jets, the minimum mass flow rate for stable flame decreased as the value of $A_{E X} / A_{I N}$ decreased. For $A_{E X} / A_{I N} \gtrsim 7$, where the jet is over-expanded, the shock wave just out of the nozzle exit is a compression wave as shown in Figure 3, and the minimum mass flow rate decreases as $A_{E X} / A_{I N}$ increases.

\section{Numerical study}

\subsection{Model details}

The effects of shock structure on velocity and hydrogen concentrations distributions were numerically studied by carrying out steady state simulations in two-dimensional axisymmetric formulation. The computational domain and enlarged image in the vicinity of nozzle outlet are shown in Figure 6. Simulated nozzle dimensions are given in Table 2 . The sizes of simulated nozzles were determined corresponding to the experimental conditions with maximum deviation within $0.01 \mathrm{~mm}$. The computational domain width was 210 $\mathrm{mm}$ and height $100 \mathrm{~mm}$. The grids had square shape, and the mesh size near the nozzle axis was set finer. The minimum grid dimension was $30 \mu \mathrm{m}$, and the number of control volumes in a grid was about 25,000. The grid convergence value of $30 \mu \mathrm{m}$ could be determined by the following procedure that the mesh sizes were repeatedly decreased half and half, and then the simulated results were compared with those with the previous mesh sizes. Boundary conditions in the simulation are shown in Table 3.

Governing equations of mass, momentum, energy and chemical species transport equations were solved using ANSYS Fluent 16.2 as computational engine. The RNG k- $\varepsilon$ model [19] was used as a turbulent model, where the model constant $C_{l \varepsilon}$ was changed from default value 1.42 to 1.64 . The value of 1.64 was selected so that the simulated hydrogen mass fraction distribution along the nozzle axis could be corresponded with the distribution estimated by the empirical equation by Li et al. [20]. In Figure 7, $Y_{h c l}$ is the hydrogen mass fraction, $z$ is the distance from nozzle exit along nozzle axis, and $d^{*}$ is defined as $d_{E X}\left(\rho_{E X} / \rho_{\infty}\right)^{0.5}$, where $\rho_{E X}$ is gas density at nozzle exit, $\rho_{\infty}$ is surrounding gas density. The value of $\rho_{E X}$ was calculated using the under-expanded jet theory [21]. As shown in Figure 7, the empirical relationship between hydrogen mass fraction and non-dimensional distance could be well reproduced when value 1.64 is used to the model constant $C_{l \varepsilon}$.

\subsection{Calculated results}

Typical results of density distributions for the static pressure in nozzle of $8 \mathrm{MPa}(m=0.98 \mathrm{~g} / \mathrm{s})$ are shown in Figure 8. The single Mach disk exists for $0.25 \leq A_{E X} / A_{I N} \leq 1.69$, and densities along the nozzle axis were 
changed rapidly adjacent to the nozzle exit. The distance $L_{M D}$ from the nozzle exit to the Mach disk for the straight nozzle of $d_{I N}=d_{E X}=0.5 \mathrm{~mm}$ is $2.82 \mathrm{~mm}$. This is just by $0.9 \mathrm{~mm}$ longer than value calculated with the empirical equation, $L_{M D} / d_{E X}=0.62\left(p_{E X} / p_{A}\right)^{0.51}$ [18]. Densities along nozzle axis for $A_{E X} / A_{I N} \gtrsim 4$ repeated increasing and decreasing downstream creating so-called diamond shock structures. Figure 9 shows the scalar of velocity vector along the nozzle axis for different ratios $A_{E X} / A_{I N}$. Jets for $A_{E X} / A_{I N} \lesssim 1.69$ have one Mach disk at position $2.80-2.85 \mathrm{~mm}$ downstream of the nozzle exit, where the scalar of velocity rapidly decreased to approximately $500 \mathrm{~m} / \mathrm{s}$. Then, the velocity gradually increased and had a peak of $1200-1700 \mathrm{~m} / \mathrm{s}$. On the other hand, jets for $A_{E X} / A_{I N} \gtrsim 4$ have multiple shock diamond structures and maintain its higher velocity of 2000-2500 $\mathrm{m} / \mathrm{s}$ for over $z=20 \mathrm{~mm}$, and then the velocity monotonically decreases downstream.

\section{Blow-off model for high-pressurized hydrogen jet flames}

In the previous study for very highly under-expanded hydrogen jet with straight nozzle, the blow-off limit could be arranged only with the flow rate of spouted hydrogen, regardless of the static pressure in nozzle or the throat diameter of nozzle $[7,8,13]$. On the other hand, it is shown in Figure 5 that the required minimum hydrogen flow rate for the flame stabilization depends upon $A_{E X} / A_{I N}$ or the structure of shock downstream of nozzle exit. An attempt would be made to interpret it by considering the distributions of velocity and concentration.

Figure 10 shows the value of $v_{\text {phil }}$, which is the velocity at an intersection point between the stoichiometric contour of hydrogen concentration in the jet and line at $z=70 \mathrm{~mm}$ perpendicular to the nozzle axis. The value $z=70 \mathrm{~mm}$ means the distance $H f b$ from the nozzle exit to the flame base for $A_{E X} / A_{I N} \gtrsim 4$ as shown in Figure 3. The value of $v_{p h i 1}$ increases as $A_{E X} / A_{I N}$ increases and becomes almost constant at $A_{E X} / A_{I N} \gtrsim 4$. The variation of $H f b$ for $A_{E X} / A_{I N} \lesssim 4$ could be explained when considering flame base position as the one where flow velocity is equal to flame propagation velocity [22], and in the assumption that the stable flame base position lies at the stoichiometric contour [4]. In other words, the velocities on the stoichiometric contour for $A_{E X} / A_{I N} \lesssim 4$ were obviously lower than those for $A_{E X} / A_{I N} \gtrsim 4$ at the same position (z=70 mm) in $z$-direction. Therefore, the flow velocity for $A_{E X} / A_{I N} \lesssim 4$ could be balanced with the turbulent burning velocity farther upstream than cases with $A_{E X} / A_{I N} \gtrsim 4$. Consequently, as shown in Figures 3 and 4, the value of $H f b$ for $A_{E X} / A_{I N}$ $\lesssim 4$ could be smaller.

The criterion required for stable non-premixed flames in subsonic jets was formulated as $H w>H f b$ [23], where $H w$ is the distance from the nozzle exit to the intersection of two lines, one being the jet axis and another being perpendicular line from the jet axis to the maximum radial location of the stoichiometric contour. The value of $H w$ could be estimated from an actual nozzle diameter, spouted and ambient gas densities by using the equations proposed by Birch et al. [24] and was validated in the literature [23]. It was reported that characteristics of under-expanded jets could be predicted using the notional nozzle theory proposed by Molkov et al. [25, 26]. The values of $H w$ calculated by the notional nozzle diameter are shown in Figure 11 [13]. This figure demonstrates that the values of $H w$ depends little on $A_{E X} / A_{I N}$ but depend on the static pressure, and that $H w$ can be determined by hydrogen flow rate regardless of nozzle types or shock structures. As the static pressure in nozzle increases, the hydrogen flow rate and $H w$ increase.

For the nozzles with the same $d_{t h r}$, when the static pressure or mass flow rate is the same, the values of $H w$ change little regardless of the type of shock structure, while the value of $H f b$ having the structure of Mach disk is clearly smaller than $H f b$ ' whose shock structure is sequential shock cell type, as shown in Figures 3 and 
4, because the value of velocity $v_{p h i 1}$ in Figure 10 increases as the increase of $A_{E X} / A_{I N}$ and becomes constant for $A_{E X} / A_{I N} \gtrsim 4$. This means that the velocity and concentration fields are not linearly linked each other, due to the variations of shock structure. The cases where the flame is stabilized and stable regardless of a type of shock structure seem to have the relationship of $H w>H f b^{\prime}>H f b$ shown in Figure 12(a). If the static pressure or mass flow rate gradually decreases, $H w$ decreases while both of $H f b$ and $H f b$ ' don't change essentially as shown in Figure 4. In this case, the relationship of $H f b^{\prime}>H w>H f b$ shown in Figure 12(b) can hold, and the flame with sequential shock cells will blow-off, while the flame with one Mach disk will be still stabilized. If the static pressure or mass flow rate decreases further, the relationship of $H f b^{\prime}>H f b>H w$ is realized and the flame will blow-off regardless of a type of shock structure. This shows qualitatively that minimum static pressure or mass flow rate required for stable flames in the high-pressurized hydrogen jet with sequential shock cell structures should be higher, as shown in Figure 5.

\section{Conclusions}

The change of cross-section area ratio $A_{E X} / A_{I N}$ changes the shock structure downstream the nozzle exit even the static pressure in the nozzle is kept the same, where the ratio $p_{E X} / p_{A}$, i.e. the ratio of nozzle exit to ambient pressure changes in conjunction. The flame lift-off length $H f b$ and the blow-off condition of the turbulent non-premixed flame for high-pressure hydrogen jets are experimentally examined, with $A_{E X} / A_{I N}=0.23$ -11.2 (minimum throat diameter is constant at $0.5 \mathrm{~mm}$ ) and hydrogen flow rate $=0.3-1.48 \mathrm{~g} / \mathrm{s}$ being parameters.

It is shown that when ratio $A_{E X} / A_{I N}$ is the same, $H f b$ for stable flames slightly depends on the static pressure. For $A_{E X} / A_{I N}<3.78\left(p_{E X} / p_{A}>2.45\right)$, a single barrel shock and Mach disk could be observed at the nozzle exit, and $H f b$ increases with the increase of $A_{E X} / A_{I N}$. On the other hand, for $A_{E X} / A_{I N} \geq 3.78\left(p_{E X} / p_{A} \leq 2.45\right)$, the sequential shock cell (diamond) structures is observed and $H f b$ was almost constant regardless of $A_{E X} / A_{I N}$, and a higher mass flow rate of hydrogen was needed for the stabilization of jet flames. Moreover, when the flow in the nozzle was close to ideal expansion $\left(A_{E X} / A_{I N}=6 \sim 7, p_{E X} / p_{A}=0.9 \sim 1.1\right)$, the mass flow rate for existence of stable flame became maximum.

The numerical simulation at static pressure of $8 \mathrm{MPa}$ demonstrated that hydrogen jets with $A_{E X} / A_{I N} \gtrsim 4$ have the sequential shock cell (diamond) structure, and the velocity at the intersection point between the stoichiometric contour and the line perpendicular to the nozzle axis at $70 \mathrm{~mm}$ downstream from the nozzle exit is almost the same. Hydrogen jets with $A_{E X} / A_{I N} \lesssim 4$ have single Mach disk and the velocity at the same point decreased with the decrease of $A_{E X} / A_{I N}$. This qualitatively explains the experimental result that the value of $H f b$ for $A_{E X} / A_{I N}<3.78\left(p_{E X} / p_{A}>2.45\right)$ decreases with the decrease of $A_{E X} / A_{I N}$.

The mass flow rate required for the existence of stable flame is almost the same for $A_{E X} / A_{I N} \geq 3.78$ and the required flow rate for $A_{E X} / A_{I N}<3.78$ decreases with the decrease of $A_{E X} / A_{I N}$. This observation could be qualitatively explained by considering the condition for stabilization of jet flame $H w>H f b$ regardless of the shock structures, where $H w$ is the distance from the nozzle axis to the maximum radius point on the stoichiometric contour.

\section{References}

[1] Acar, C. and Dincer, I. Comparative assessment of hydrogen production methods from renewable and non-renewable sources. International Journal of Hydrogen Energy 2014;39:1-12. 
[2] Mazloomi, K. and Gomes, C. Hydrogen as an energy carrier: Prospects and challenges. Renewable and Sustainable Energy Reviews 2012;16:3024-3033.

[3] Kojima, H., Matsumoto, H. and Tsujimura, T. Development of large scale unified system for hydrogen energy carrier production and utilization: Experimental analysis and systems modelling. International Journal of Hydrogen Energy 2017;42(19): 13309-14044.

[4] Annushkin, Y. M. and Sverdlov, E.D. Stability of submerged flames in subsonic and underexpanded supersonic gas-fuel streams. Combustion Explosion and Shock Waves 1979;14(5):597-605.

[5] Yoon, Y., Donbar, J. M. and Driscool, J. F. Blow-out stability limits of a hydrogen jet flame in a supersonic heated coflowing air stream. Combustion Science and Technology 1994;97(1-3):137-156.

[6] Wu, Y., Lu, Y., Al-Rahbia, I. S. and Kalghatgi, G.T. Prediction of the liftoff, blowout and blowoff stability limits of pure hydrogen and hydrogen/hydrocarbon mixture jet flames. International Journal of Hydrogen Energy 2009;34(14):5940-5945.

[7] Takeno, K. Characteristics and safety for open-jet flame of high-pressurized hydrogen. Journal of the Combustion Society of Japan 2010;52(160):121-129.

[8] Takeno, K., Okabayashi, K., Hashiguchi, K., Noguchi, F. and Chitose, K. Experimental Study on open jet diffusion flame of 40MPa high-pressure hydrogen. Environmental Management 2005;41:33-40.

[9] Takeno, K., Hashiguchi, K., Okabayashi, K., Chitose, K., Kushiyama, M. and Noguchi, F. Experimental study on open jet diffusion flame and unconfined explosion for leaked high-pressurized hydrogen. Journal of Japan Society for Safety Engineering 2005;44:398-406.

[10] Takeno, K., Okabayashi, K., Kouchi, A., Nonaka, T., Hashiguchi, K. and Chitose, K. Dispersion and explosion field tests for 40MPa pressurized hydrogen. International Journal of Hydrogen Energy 2007;32:2144-2153.

[11] Kouchi, A., Okabayashi, K., Takeno, K. and Chitose, K. Dispersion tests on concentration and its fluctuation for 40MPa pressurized hydrogen. Proceeding of International Conference on Hydrogen Safety, Sep. 8-10, 2007, Pisa, Italy.

[12] Takeno, K., Okabayashi, K., Kouchi, A., Misaka, N. and Hashiguchi, K. Concentration Fluctuation and Ignition Characteristics during Atmospheric Diffusion of Hydrogen Spouted from high Pressure Storage. International Journal of Hydrogen Energy 2017;42(22):15426-15434.

[13] Yamamoto, S., Sakatsume, R. and Takeno, K. Blow-off process of highly under-expanded hydrogen non-premixed jet flame. International Journal of Hydrogen Energy 2018;43(10):5199-5205.

[14] Crist, S., Glass, D.R. and Sherman P.M. Study of the highly underexpanded sonic jet. AIAA Journal 1966;4(1):68-71.

[15] Andre, B., Castelain, T. and Bailly, C. Experimental exploration of underexpanded supersonic jets. Shock Waves 2013;24(1):21-32.

[16] Rogers, T., Petersen, P., Koopmans, L., Lappas, P. and Boretti, A. Structural characteristics of hydrogen and compressed natural gas fuel jets. International Journal of Hydrogen Energy 2015;40(3):1584-1597.

[17] Li, X., Wu, K., Yao, W. and Fan, X. A comparative study of highly underexpanded nitrogen hydrogen jets using large eddy simulation. International Journal of Hydrogen Energy 2016;41(9):5151-5161.

[18] Franquet, E., Perrier, V., Gibout, S. and Bruel, P. Free underexpanded jets in a quiescent medium: A review. Progress in Aerospace Sciences 2015;77:25-53.

[19] Yakhot, V. and Orszag, S.A. Renormalization Group Analysis of Turbulence. I. Basic Theory. Journal of 
Scientific Computing 1986;1(1):3-51

[20] Li, X., Hecht, E.S. and Christopher, D.M. Validation of a reduced-order jet model for subsonic and underexpanded hydrogen jets. International Journal of Hydrogen Energy 2016;41:1348-1358.

[21] Molkov, V. and Bragin, M. High-pressure hydrogen leak through a narrow channel. In: Nonequilibrium Phenomena: Plasma, Combustion, Atmosphere, Moscow, 2009;332-338.

[22] Chung, S.H. Stabilization, propagation and instability of tribrachial triple flames. Proceedings of the Combustion Institute 2007;31:877-892.

[23] Wu, C. Y., Chao, Y. C., Cheng, T. S., Li, Y. H., Lee, K. Y. and Yuan, T. The blowout mechanism of turbulent jet diffusion flames. Combustion and Flame 2006;145(3):481-494.

[24] Birch, A. D., Brown, D. R., Dodson, M. G. and Thomas, J. R. The turbulent concentration field of a methane jet. Journal of Fluid Mechanics 1978;88(3):431-449.

[25] Molkov, V., Makarov, D. and Bragin, M. Physics and modelling of under-expanded jets and hydrogen dispersion in atmosphere. Physics of extreme state of matter 2009:143-145.

[26] Molkov, V., Shentsov, V., Brennan, S. and Makarov, D. Hydrogen non-premixed combustion in enclosure with one vent and sustained release: Numerical experiments. International Journal of Hydrogen Energy 2014;39:10788-10801. 


\section{Captions to figures}

Figure 1. Schematic diagram of experimental set up.

Figure 2. Cross-section drawings of three types of nozzles.

Figure 3. Schlieren images of turbulent non-premixed jet flames with different ratio of the exit cross-section area of nozzle to the inlet cross-section area, $A_{E X} / A_{I N}$, with the hydrogen mass flow rates kept almost constant. The right figures are the enlarged schlieren images focused on the shock structures near the nozzle exit.

Figure 4. Dependence of lift-off length $H f b$ on $A_{E X} / A_{I N}$.

Figure 5. Conditions for hydrogen flame stabilization $(\circ)$, and blow-off $(\times)$.

Figure 6. Computational domain and enlarged image near the nozzle exit.

Figure 7. Change in the reciprocal of $\mathrm{H}_{2}$ mass fraction $Y_{h c l}$ along the non-dimensional jet axis with changing RNG $k-\varepsilon$ turbulence model coefficient $C_{l \varepsilon}$.

Figure 8. Simulation results of density contour near the nozzle exit, with the static pressure and mass flow rate set at $8 \mathrm{MPa}$ and $0.98 \mathrm{~g} / \mathrm{s}$, respectively.

Figure 9. Simulation results of velocity distribution along the jet axis, where the calculation conditions correspond to those of Figure 8.

Figure 10. Simulation results of velocity $v_{p h i 1}$ at the intersection point between the stoichiometric contour and $\mathrm{z}=70 \mathrm{~mm}$ line perpendicular to the jet axis.

Figure 11. Relationship between $H w$ and $A_{E X} / A_{I N}$ with the variation of static pressure in nozzle, where the

Figure 12. Schematic illustrations on the relationship between $H f b$ and $H w$ and qualitative model for blow-off or stable flame.

\section{Caption to tables}

Table 1. Types and dimensions of used nozzles.

Table 2. Nozzle dimensions in numerical simulations.

Table 3. Boundary conditions of simulations. 


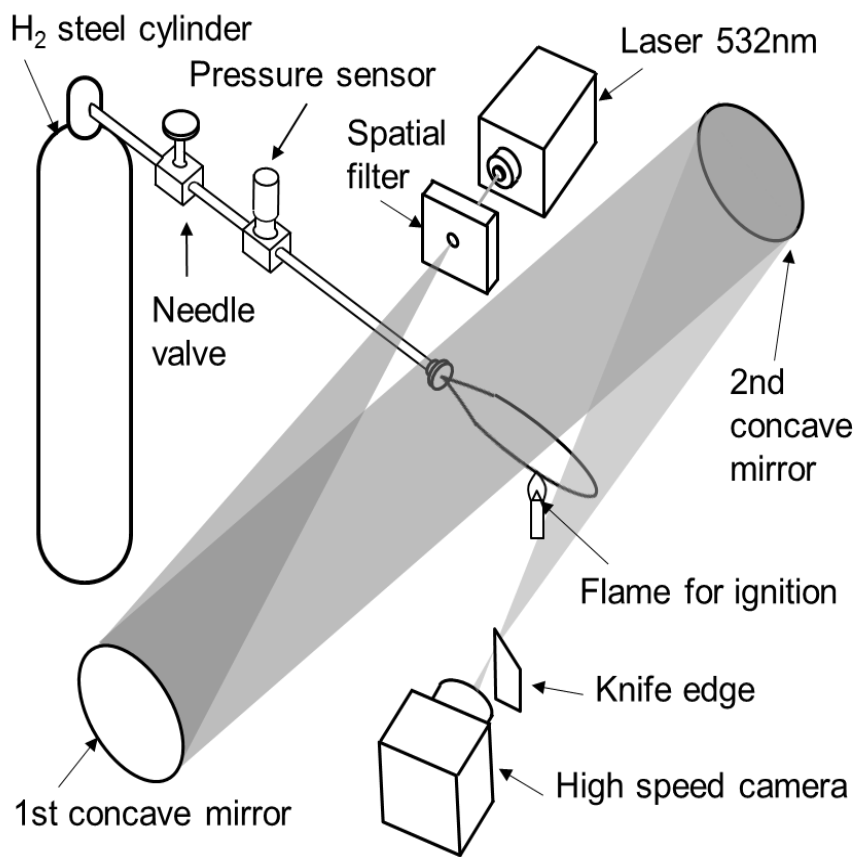

Figure 1. Schematic diagram of experimental set up.
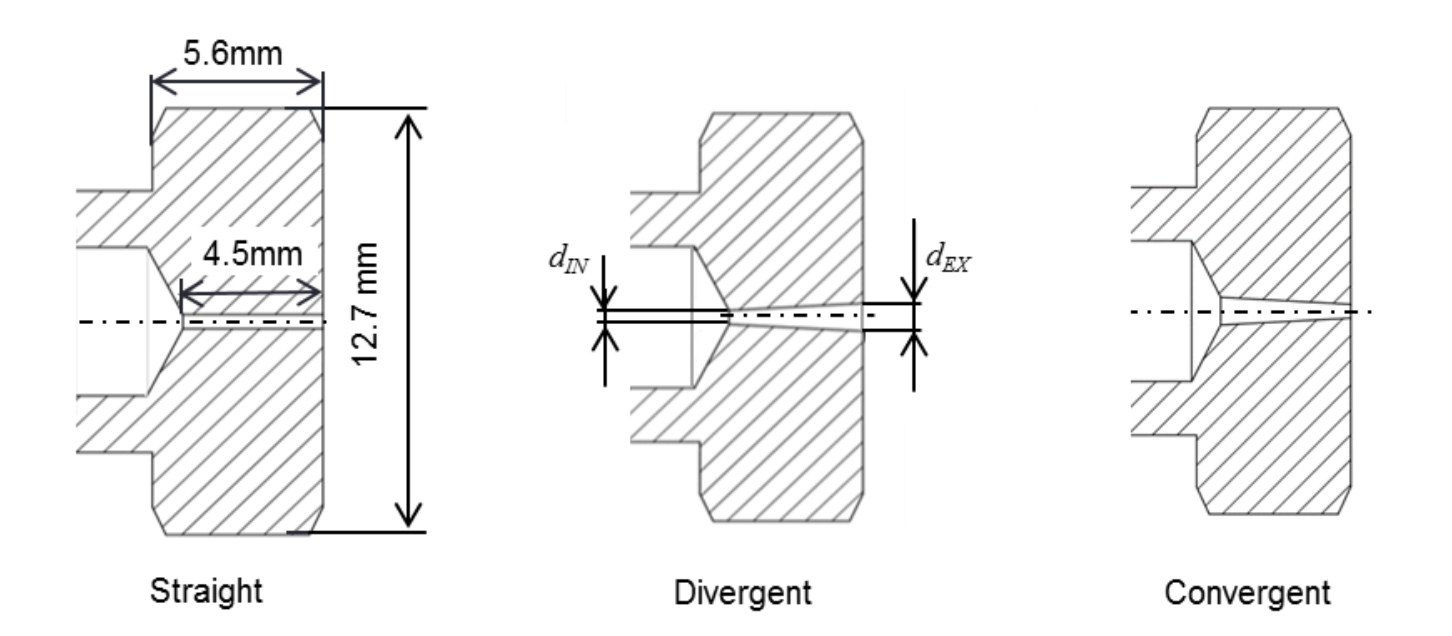

Figure 2. Cross-section drawings of three types of nozzles. 
Table 1. Types and dimensions of used nozzles.

\begin{tabular}{|l|l|c|c|c|c|c|}
\hline \multirow{3}{*}{ Nozzle type } & \multirow{2}{*}{ Abbreviation } & \multicolumn{2}{|c|}{ INLET } & \multicolumn{2}{c|}{ EXIT } & \multirow{2}{*}{$A_{E X} / A_{I N}$} \\
\cline { 3 - 7 } & & $d_{I N}[\mathrm{~mm}]$ & $A_{I N}\left[\mathrm{~mm}^{2}\right]$ & $d_{E X}[\mathrm{~mm}]$ & $A_{E X}\left[\mathrm{~mm}^{2}\right]$ & \\
\hline \multirow{4}{*}{ Straight } & $\mathrm{d} 0.3$ & 0.31 & 0.08 & 0.34 & 0.09 & 1.20 \\
\cline { 2 - 7 } & $\mathrm{d} 0.5$ & 0.51 & 0.20 & 0.53 & 0.22 & 1.09 \\
\cline { 2 - 7 } & $\mathrm{d} 0.7$ & 0.73 & 0.41 & 0.75 & 0.44 & 1.06 \\
\hline \multirow{5}{*}{ Divergent } & $\mathrm{d} 0.5-0.65$ & 0.52 & 0.21 & 0.66 & 0.34 & 1.62 \\
\cline { 2 - 7 } & $\mathrm{d} 0.5-0.80$ & 0.53 & 0.22 & 0.81 & 0.52 & 2.40 \\
\cline { 2 - 7 } & $\mathrm{d} 0.5-1.00$ & 0.52 & 0.21 & 1.01 & 0.79 & 3.78 \\
\cline { 2 - 7 } & $\mathrm{d} 0.5-1.30$ & 0.52 & 0.21 & 1.32 & 1.36 & 6.44 \\
\cline { 2 - 7 } & $\mathrm{d} 0.5-1.60$ & 0.52 & 0.22 & 1.64 & 2.10 & 9.73 \\
\cline { 2 - 6 } & $\mathrm{d} 0.5-1.65$ & 0.51 & 0.20 & 1.70 & 2.28 & 11.2 \\
\hline Convergent & $\mathrm{d} 1.00-0.5$ & 1.04 & 0.85 & 0.50 & 0.19 & 0.23 \\
\hline
\end{tabular}




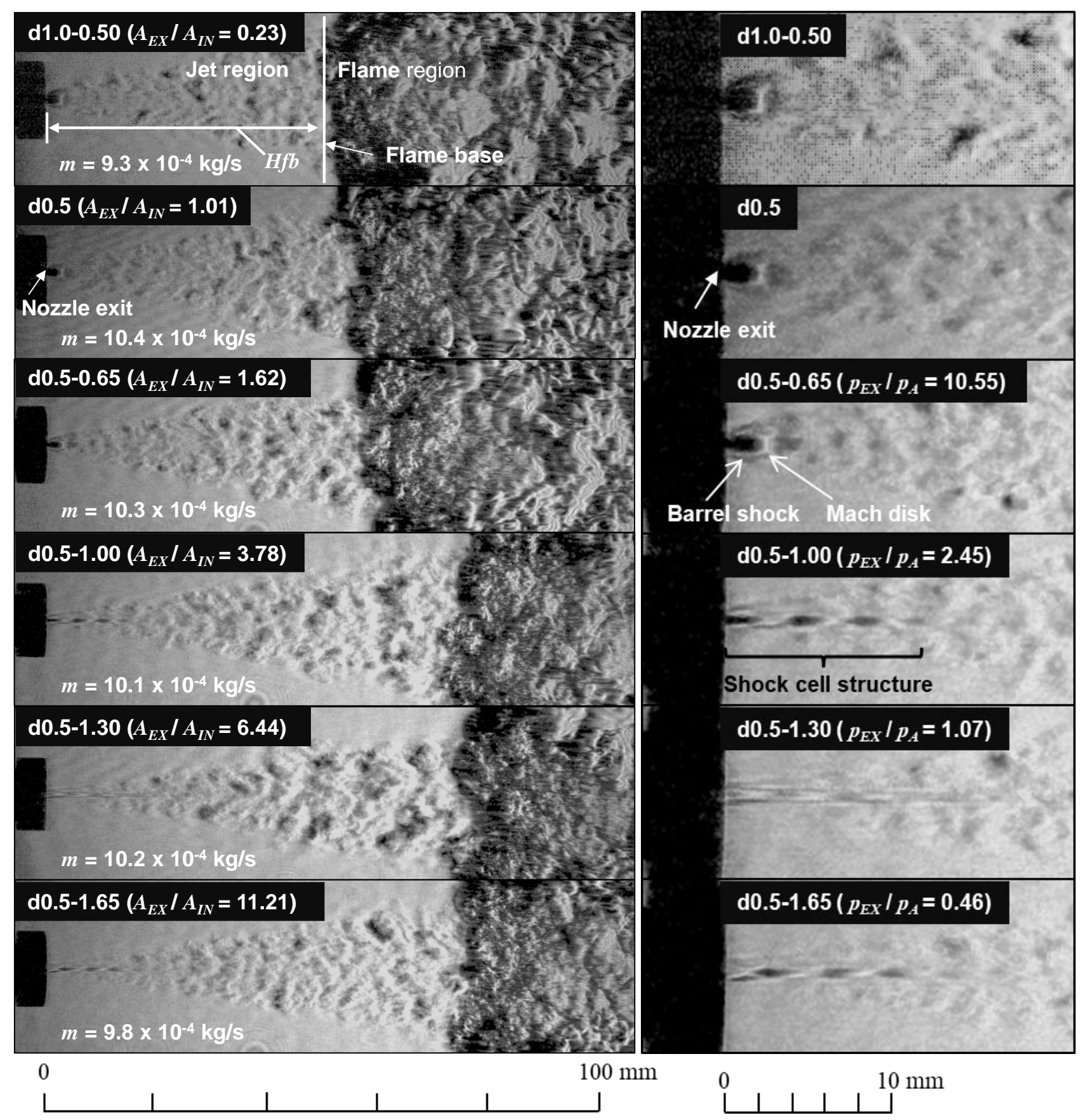

Figure 3. Schlieren images of turbulent non-premixed jet flames with different ratio of the exit cross-section area of nozzle to the inlet cross-section area, $A_{E X} / A_{I N}$, with the hydrogen mass flow rates kept almost constant. The right figures are the enlarged schlieren images focused on the shock structures near the nozzle exit. 


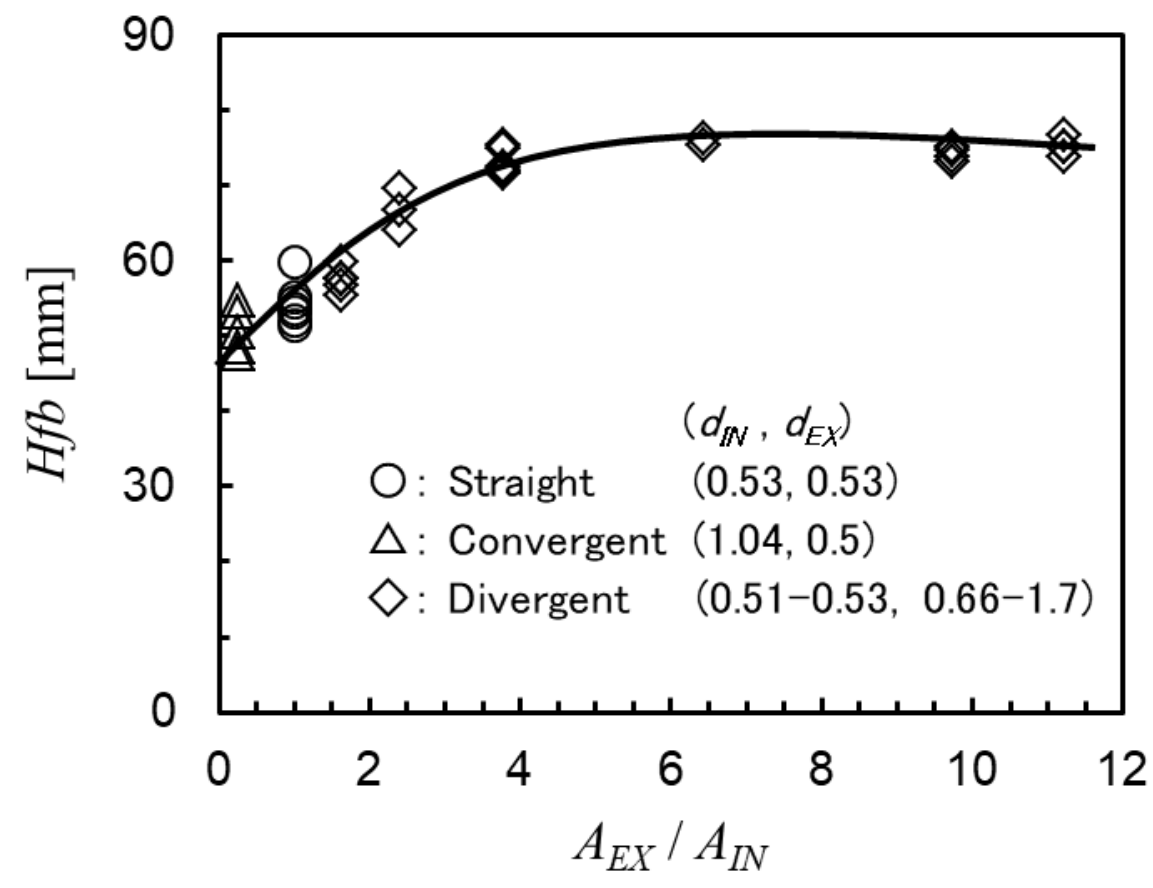

Figure 4. Dependence of lift-off length $H f b$ on $A_{E X} / A_{I N}$.

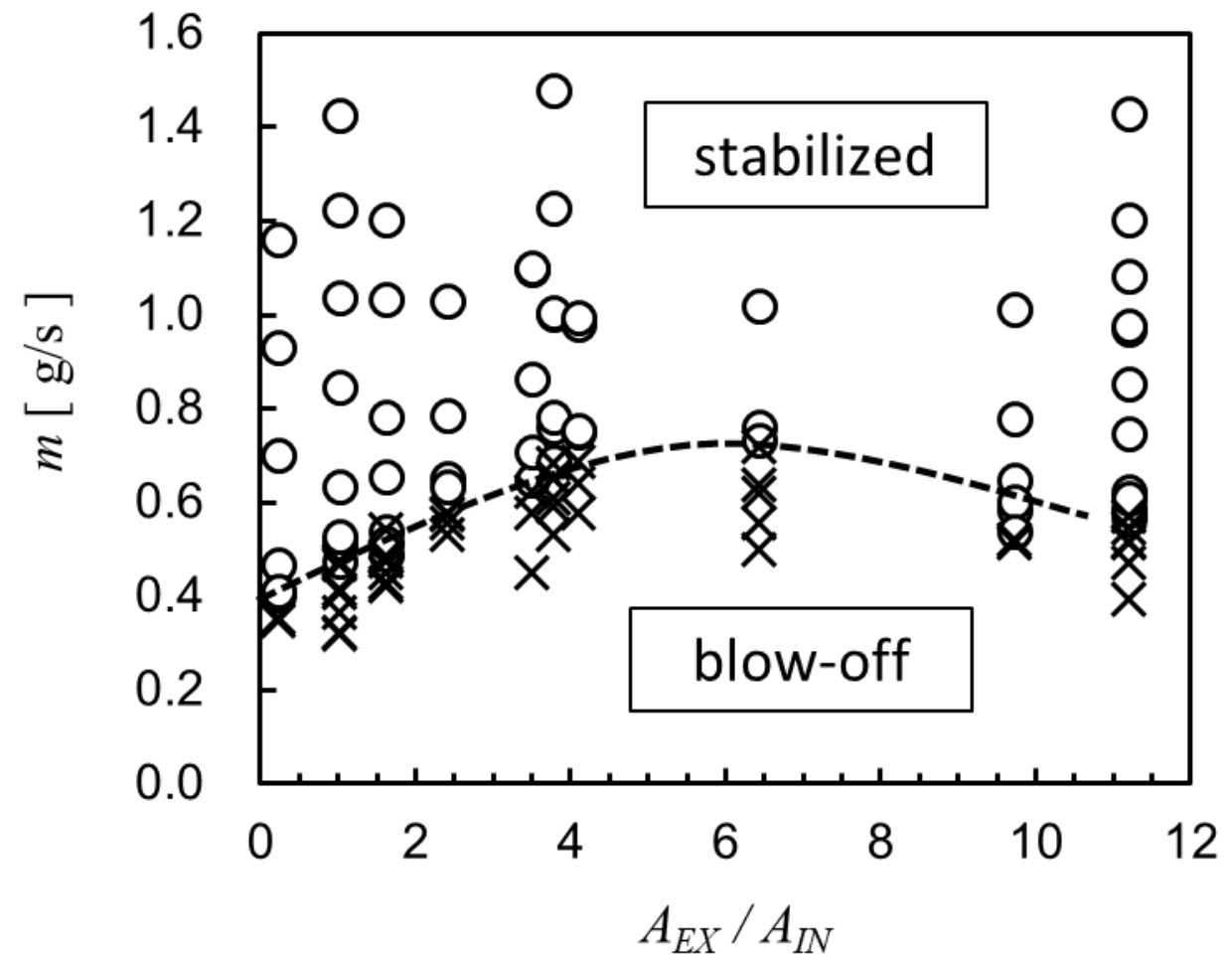

Figure 5. Conditions for hydrogen flame stabilization (०), and blow-off $(\times)$. 


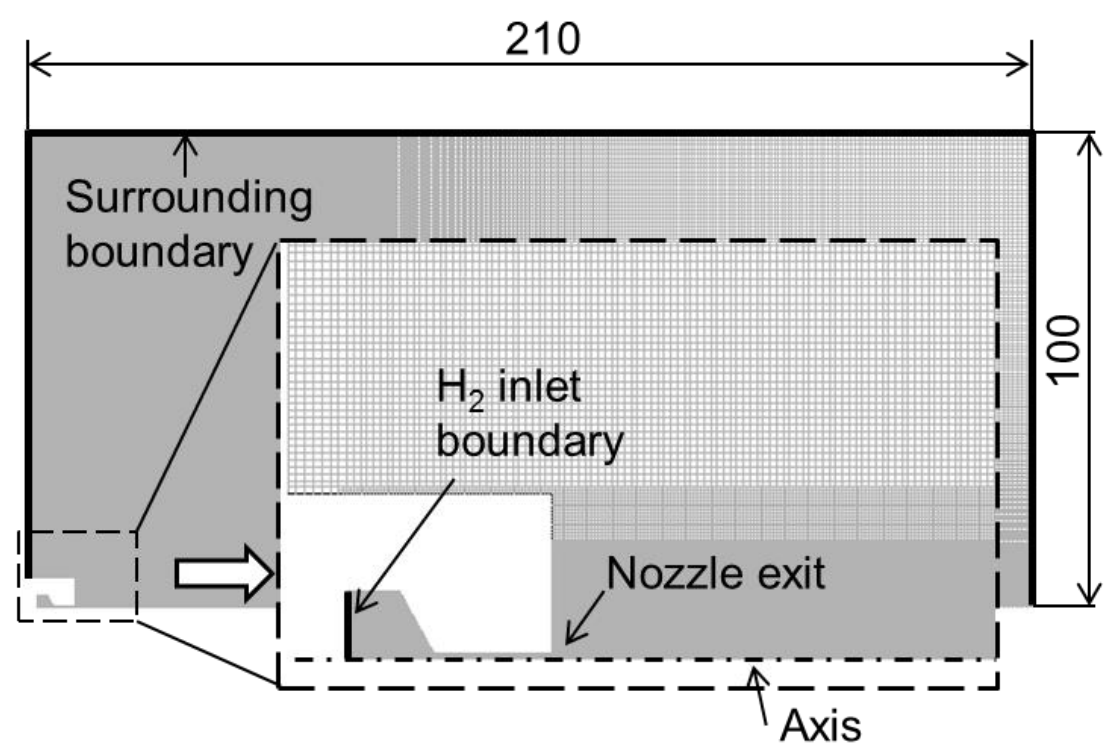

Figure 6. Computational domain and enlarged image near the nozzle exit.

Table 2. Nozzle dimensions in numerical simulations.

\begin{tabular}{|l|c|c|c|}
\hline Nozzle type & $d_{I N}[\mathrm{~mm}]$ & $d_{E X}[\mathrm{~mm}]$ & $A_{E X} / A_{I N}$ \\
\hline Straight & 0.50 & 0.50 & 1.00 \\
\hline \multirow{5}{*}{ Divergent } & 0.50 & 0.65 & 1.69 \\
\cline { 2 - 4 } & 0.50 & 0.80 & 2.56 \\
\cline { 2 - 4 } & 0.50 & 1.00 & 4.00 \\
\cline { 2 - 4 } & 0.50 & 1.16 & 5.38 \\
\cline { 2 - 4 } & 0.50 & 1.30 & 6.76 \\
\cline { 2 - 4 } & 0.50 & 1.50 & 9.00 \\
\cline { 2 - 4 } & 0.50 & 1.65 & 10.9 \\
\hline Convergent & 1.00 & 0.50 & 0.25 \\
\hline
\end{tabular}

Table 3. Boundary conditions of simulations.

\begin{tabular}{|c|c|c|}
\hline & $\mathrm{H} 2$ inlet & Surrounding \\
\hline Temperature $[\mathrm{K}]$ & 300 & 300 \\
\hline $\begin{array}{c}\text { Absolute pressure } \\
{[\mathrm{MPa}]}\end{array}$ & 3 to 10 & 0.1 \\
\hline $\begin{array}{c}\text { Composition } \\
\text { (Mass fraction) }\end{array}$ & $1 \mathrm{H}_{2}$ & $0.23 \mathrm{O}_{2}$ \\
$0.77 \mathrm{~N}_{2}$ \\
\hline
\end{tabular}




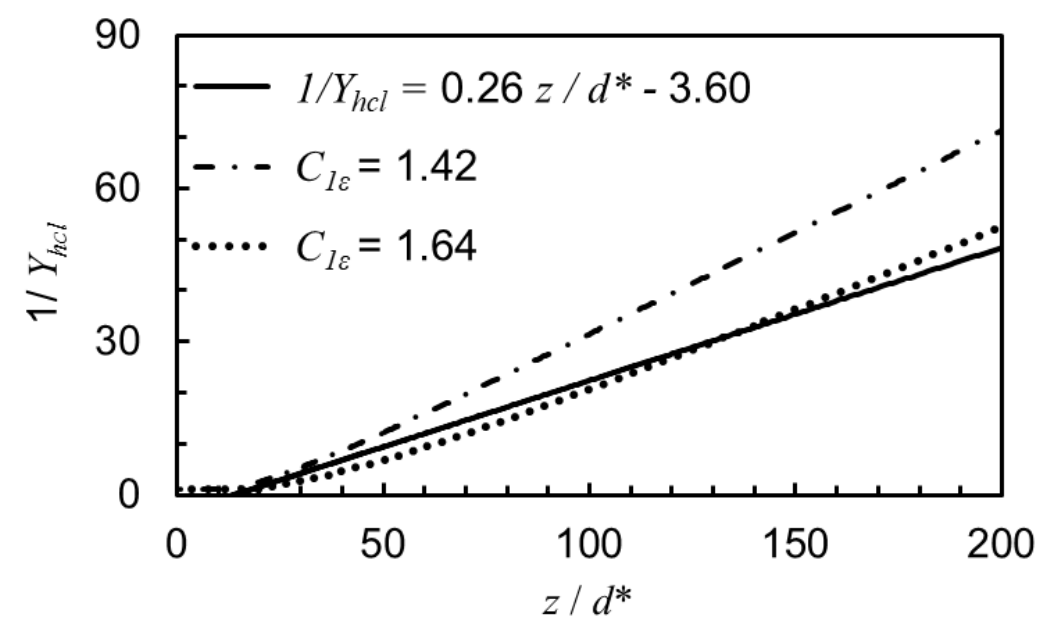

Figure 7. Change in the reciprocal of $\mathrm{H}_{2}$ mass fraction $Y_{h c l}$ along the non-dimensional jet axis with changing RNG $k$ - $\varepsilon$ turbulence model coefficient $C_{l \varepsilon}$.

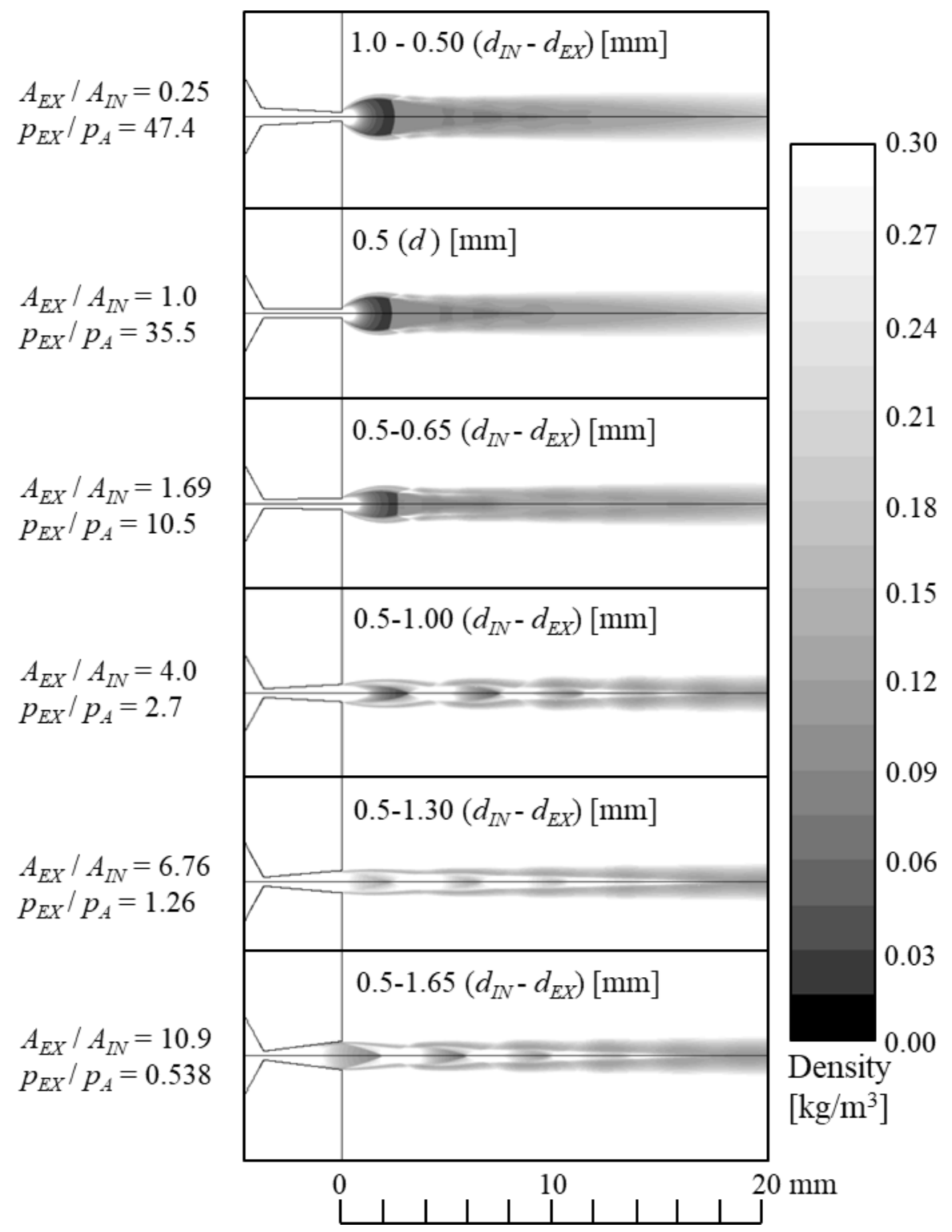

Figure 8. Simulation results of density contour near the nozzle exit, with the static pressure and mass flow rate set at $8 \mathrm{MPa}$ and $0.98 \mathrm{~g} / \mathrm{s}$, respectively. 


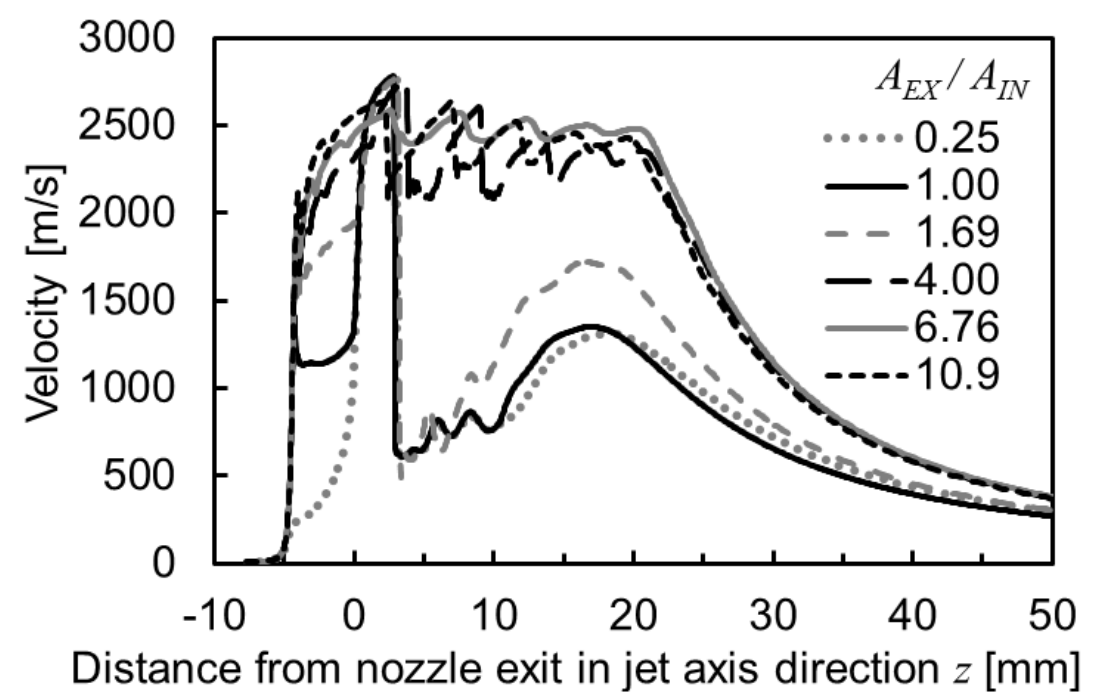

Figure 9. Simulation results of velocity distribution along the jet axis, where the calculation conditions correspond to those of Figure 8.

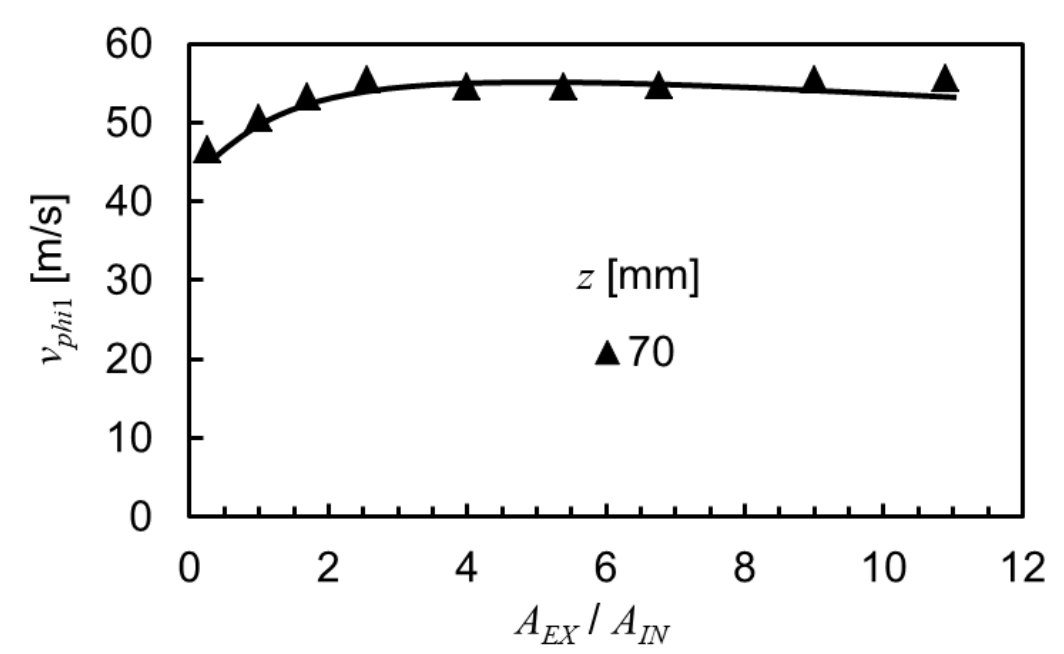

Figure 10. Simulation results of velocity $v_{p h i l}$ at the intersection point between the stoichiometric contour and $\mathrm{z}=70 \mathrm{~mm}$ line perpendicular to the jet axis. 


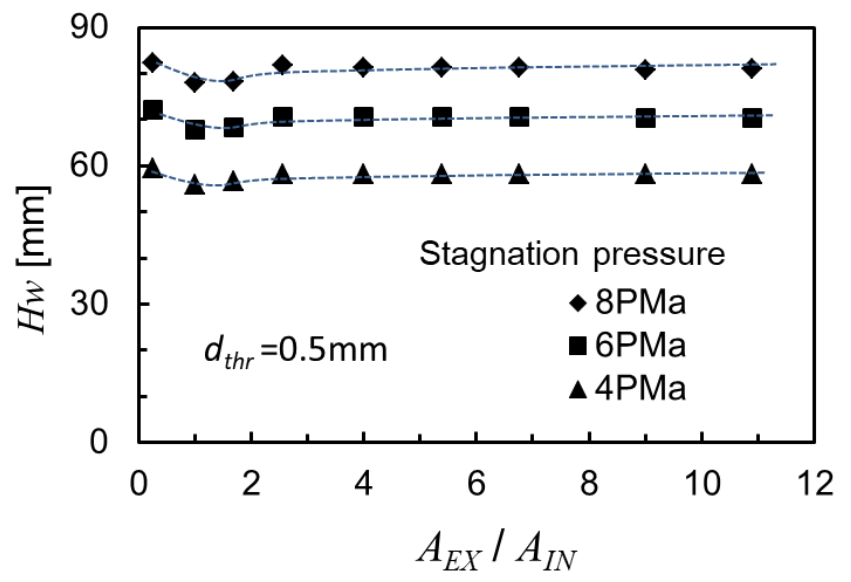

Figure 11. Relationship between $H w$ and $A_{E X} / A_{I N}$ with the variation of static pressure in nozzle, where the minimum throat diameter is constant.

(a) Stable flame condition

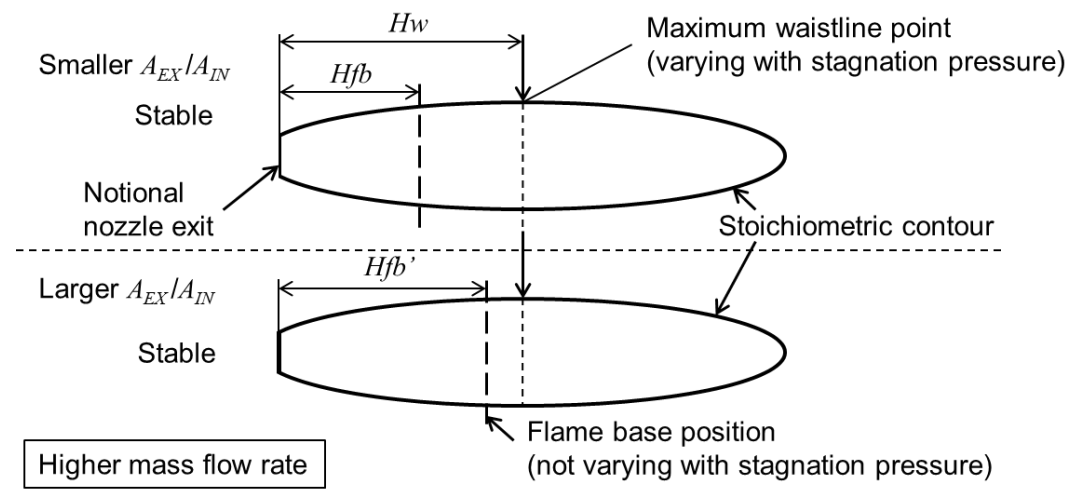

(b) Blow-off condition

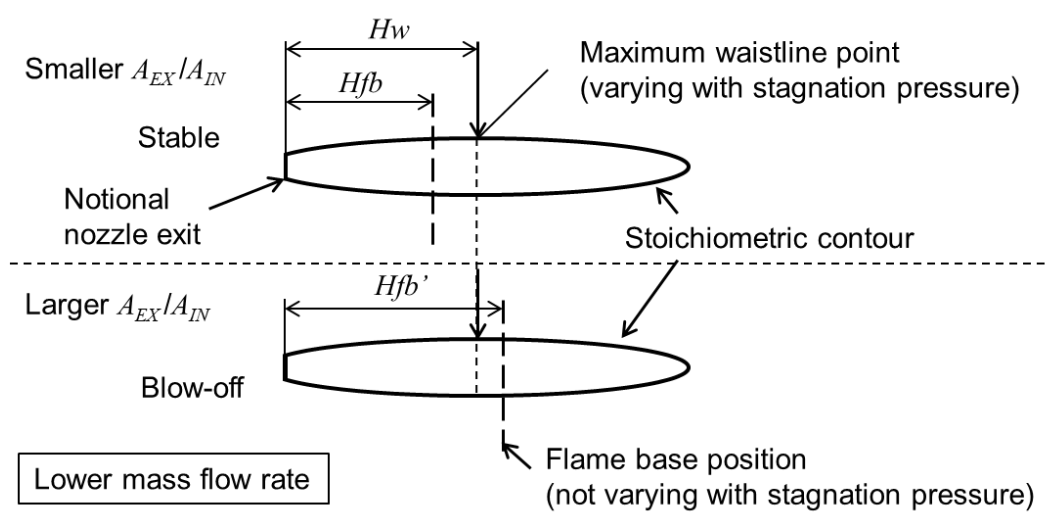

Figure 12. Schematic illustrations on the relationship between $H f b$ and $H w$ and qualitative model for blow-off or stable flame. 


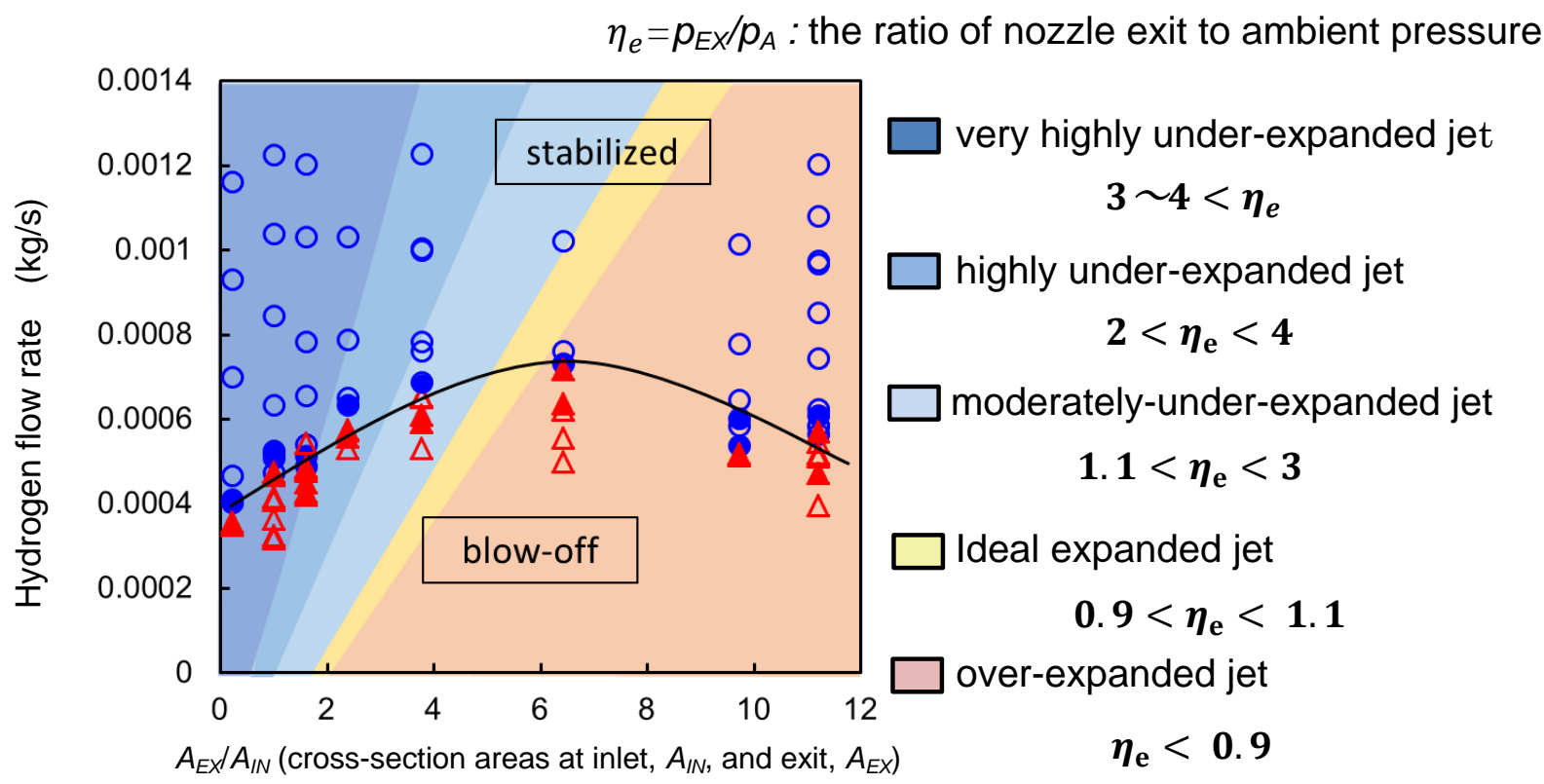

